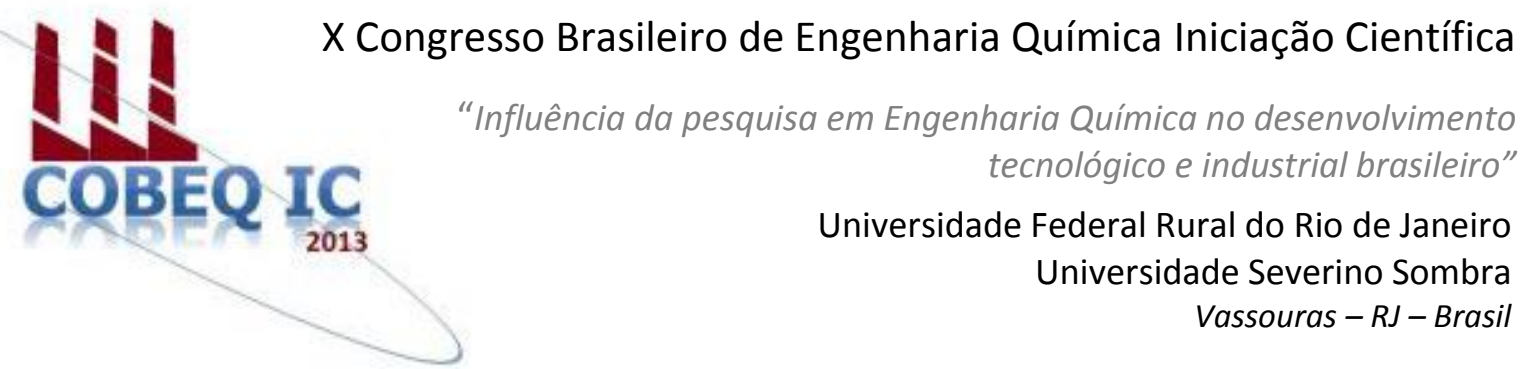

\title{
ESTUDO DA CINÉTICA DE ADSORÇÃO DE EFLUENTE DE PRODUÇÃO DE BIODIESEL EM CARVÃO ATIVADO DE OSSO BOVINO
}

\author{
M. T. $\operatorname{COSTA}^{1}$; D. C. HENRIQUE ${ }^{1}$, A. S. PEITER ${ }^{2}$, L. MEILI' ${ }^{2}$, J. I. SOLETTI ${ }^{2}$, J. L. G. \\ MARINHO $^{2}$, S. H. V. CARVALHO \\ ${ }^{1}$ Bolsista de Iniciação científica Ufal ${ }^{2}$ Docente Ufal \\ CTEC/UFAL - Universidade Federal de Alagoas \\ e-mail: lucas.meili@ctec.ufal.br
}

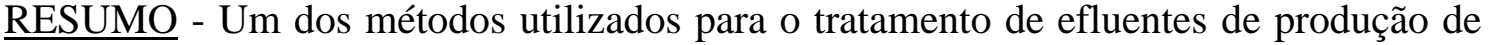
biodiesel é a adsorção, cujo processo consiste na remoção de contaminantes a partir da utilização de um agente adsorvente, sendo bastante utilizada em processos de purificação e separação, mostrando-se eficaz e econômica. Dentre os diversos resíduos passíveis de utilização como agente adsorvente está o carvão ativado, obtido pelo processo de ativação física a elevadas temperaturas proporcionando uma alta área superficial, formada por poros distribuídos uniformemente. Os resultados desse processo, cujo objetivo está na verificação do poder de adsorção do carvão ativado em efluentes de produção de biodiesel, foram avaliados utilizando modelos de Lagergren pseudo primeira ordem e pseudo segunda ordem, ajustados no software Statistica 9.0, apresentando-se satisfatórios para o estudo realizado.
\end{abstract}

Palavras chave: purificação, resíduo, adsorvente

\section{INTRODUÇÃO}

A produção de biodiesel gera um efluente líquido proveniente da etapa de purificação (lavagem ácida), que tem como principais constituintes: metanol, glicerina e biodiesel. Os corpos receptores que são contaminados por esse tipo de efluente podem sofrer danos irreparáveis a sua biodiversidade. Assim, faz-se necessário o estudo de uma forma para o tratamento desse efluente (Neves, 2009).

Um dos métodos em evidência é a adsorção, fenômeno de superfície decorrente da aderência de moléculas de um componente presente em uma fase fluida (líquida ou gasosa) sobre a superfície de um sólido. O material sólido capaz de adsorver é chamado de adsorvente, enquanto o material da fase fluida capaz de ser adsorvido é chamado adsorvato (Loureiro, 2012).

O carvão ativado é um dos agentes adsorventes que podem ser utilizados no tratamento de efluentes resultantes da produção de biodiesel, sendo um material carbonáceo, caracterizado por possuir área superficial interna elevada e porosidade altamente desenvolvida (Coutinho et al., 2000).

Nos últimos anos, vários tipos de carvão ativado foram elaborados a partir de materiais precursores de baixo custo que são, 
principalmente, resíduos vegetais, tais como casca de avelã, casca de noz (Aygünet al. 2003), fibra de palma (Tan et al., 2007), casca de laranja (Khaled et al., 2009), casca de coco (Namasivayam e Kavitha, 2002) e casca de arroz (Malik, 2003).

$\mathrm{O}$ estudo realizado busca a demonstração do poder de adsorção do carvão ativado em efluentes resultantes da produção de biodiesel, através da observação do comportamento cinético.

\section{METODOLOGIA}

A curva da cinética de adsorção do biodiesel foi realizada utilizando 0,5 gramas de carvão ativado obtidos da empresa BONECHAR - CARVÃO ATIVADO DO BRASIL LTDA., posto em contato com a emulsão formada por $500 \mathrm{~mL}$ de água destilada e $0,030 \mathrm{~g}$ de biodiesel. O sistema foi agitado em reator a $300 \mathrm{rpm}$ e a temperatura controlada de $30^{\circ} \mathrm{C}$, considerada ideal para os processos de adsorção segundo Souza (2007). As amostras foram retiradas em intervalos de 10 minutos durante 1 hora e a concentração do óleo foi avaliada. A quantidade adsorvida no tempo $t, q_{t}$, foi calculada pela Equação 1,

$$
q_{t}=\frac{\left(C_{0}-C_{t}\right) V}{W}
$$

ondeCt é a concentração do óleo na fase líquida em qualquer tempo, $\mathrm{C}_{0}$ é a concentração inicial da solução, $\mathrm{V}$ é o volume da solução e W é a massa do agente adsorvente. Os modelos para ajustar os dados de cinética de adsorção foram o de pseudo primeira ordem e o de pseudo segunda ordem, (Lagergren, 1898; Ho and McKay, 1978), utilizando o software Statistica 9.0. A Equação 2 e a Equação 3 representam estes modelos,

$$
\begin{aligned}
& q_{t}=q_{e}\left[1-\exp \left(-k_{1} t\right)\right](2) \\
& q_{t}=\frac{k_{2} q_{e}^{2} t}{1+k_{2} q_{e} t}
\end{aligned}
$$

Onde $\mathrm{k}_{1}\left(\mathrm{~min}^{-1}\right)$ e $\mathrm{k}_{2}\left(\mathrm{~g} \mathrm{mg}^{-1} \min ^{-1}\right)$ são constantes de pseudo primeira-ordem e pseudo segunda-ordem, respectivamente, $\mathrm{q}_{\mathrm{t}}\left(\mathrm{mg} \mathrm{g}^{-1}\right)$ é quantidade adsorvida no tempo $\mathrm{t}$ e $\mathrm{q}_{\mathrm{e}}\left(\mathrm{mg} \mathrm{g}^{-1}\right)$, a quantidade adsorvida no equilíbrio.

As concentrações foram avaliadas utilizando o equipamento Horiba, que utiliza o solvente S-316 para a extração do óleo.

\section{RESULTADOS E DISCUSSÕES}

A empresa fornecedora do carvão ativado analisou-o, verificando as propriedades físico-químicas descritas na Tabela 1.

Tabela 1: Propriedades físico-químicas do carvão ativado

\begin{tabular}{|c|c|}
\hline Propriedade & Especificação \\
\hline $\mathrm{pH}$ & $8,5-9,5$ \\
\hline $\begin{array}{c}\text { Área superficial } \\
\text { específica total } \\
\left(\text { BET N }^{2}\right)\end{array}$ & $200 \mathrm{~m}^{2} / \mathrm{g}$ \\
\hline $\begin{array}{c}\text { Área superficial do } \\
\text { Carbono }\end{array}$ & $50 \mathrm{~m}^{2} / \mathrm{g}$ \\
\hline Tamanho de poro & $7,5-60.000 \mathrm{~nm}$ \\
\hline Volume do poro & $0,225 \mathrm{~cm}^{2} / \mathrm{g}$ \\
\hline Aspecto & $\begin{array}{c}\text { Sólido granulado e } \\
\text { em pó }\end{array}$ \\
\hline
\end{tabular}

A emulsão formada apresentou uma concentração inicial de $60 \mathrm{ppm}$ e as concentrações avaliadas após o processo de adsorção encontram-se na Tabela 2.

Tabela 2: Dados relativos à adsorção utilizando carvão ativado

\begin{tabular}{|c|c|}
\hline Tempo (min) & $\mathrm{C}(\mathrm{ppm})$ \\
\hline 10 & 51,00 \\
\hline 20 & 32,40 \\
\hline 30 & 24,40 \\
\hline 40 & 24,70 \\
\hline 50 & 27,05 \\
\hline 60 & 25,50 \\
\hline
\end{tabular}

É possível perceber que o equilíbrio de adsorção ocorre após 30 minutos de agitação, alcançando a saturação do agente adsorvente.

Este comportamento pode ser facilmente visualizado através da Figura 1. 


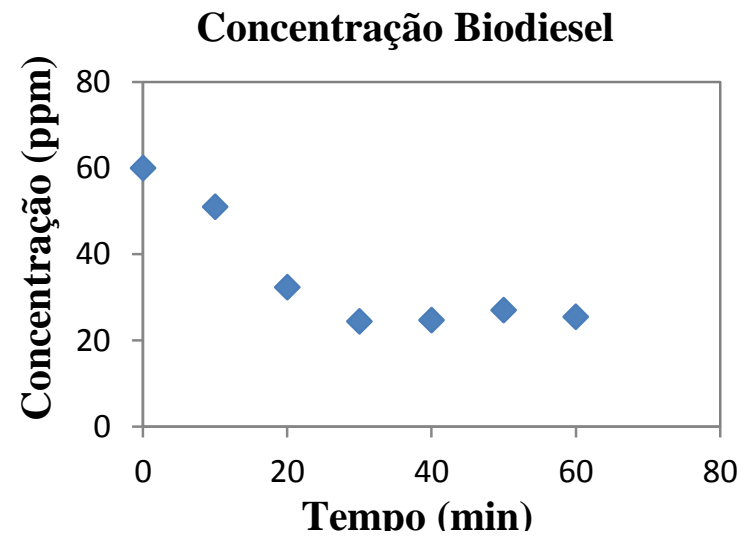

Figura 1: Concentração do efluente em função do tempo de contato com carvão ativado

A quantidade adsorvida ao longo do tempo torna-se aproximadamente constante após 30 minutos de adsorção e está apresentada na Tabela 3 .

Tabela 3: Quantidade adsorvida ao longo do tempo

\begin{tabular}{|c|c|}
\hline Tempo (min) & $\mathrm{q}_{\mathrm{t}}$ \\
\hline 10 & 9,0 \\
\hline 20 & 27,6 \\
\hline 30 & 35,6 \\
\hline 40 & 35,3 \\
\hline 50 & 33,0 \\
\hline 60 & 34,5 \\
\hline
\end{tabular}

Os dados obtidos foram ajustados utilizando o software Statistica 9.0, através dos modelos de pseudo primeira-ordem e pseudo segunda-ordem. Na Figura 2 e na Tabela 4 estão apresentados os ajustes.

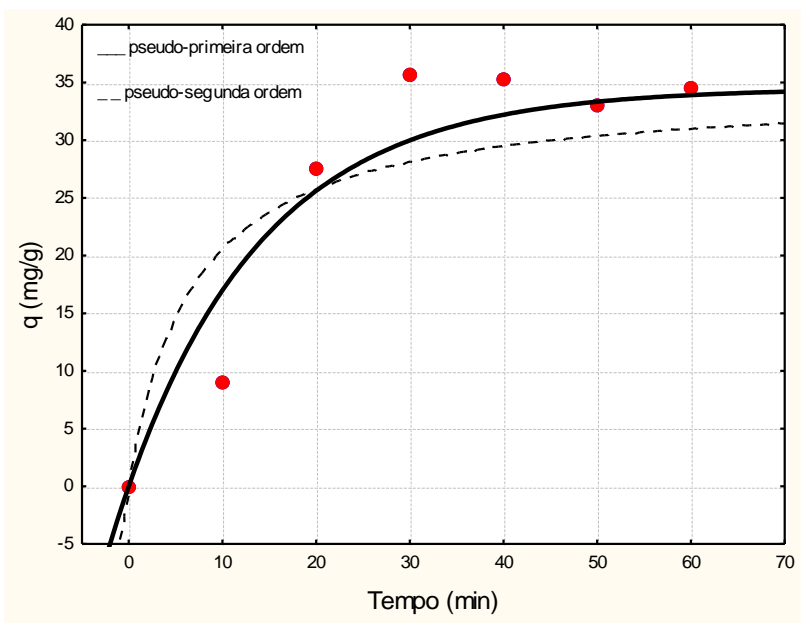

Figura 2: Ajustes dos modelos aos dados obtidos
Tabela 4: Ajustes dos dados obtidos aos modelos adotados

\begin{tabular}{|c|c|}
\hline Modelo & $\begin{array}{c}\text { Pseudo primeira- } \\
\text { ordem }\end{array}$ \\
\hline $\mathrm{K}\left(\mathrm{min}^{-1}\right)$ & 0,067797 \\
\hline $\mathrm{R}(\%)$ & 95,6 \\
\hline Modelo & $\begin{array}{c}\text { Pseudo segunda- } \\
\text { ordem }\end{array}$ \\
\hline $\mathrm{K}\left(\mathrm{g} \mathrm{mg}^{-1} \mathrm{~min}^{-1}\right)$ & 0,004274 \\
\hline $\mathrm{R}(\%)$ & 59,7 \\
\hline
\end{tabular}

O modelo de pseudo primeira-ordem se ajustou de forma mais adequada em comparação ao modelo de pseudo segundaordem.

Para Niedersberg (2012), o carvão ativado na menor faixa granulométrica estudada $(<0,5$ $\mathrm{mm}$ ) apresentou uma maior capacidade de adsorção, o que pode ser explicado pela maior área superficial fornecida para a deposição das moléculas.

Segundo Fernandez (2005), o carvão ativado apresentou bom desempenho na remoção de fenol em solução aquosa, visto uma adsorção rápida nas primeiras 10 horas de contato, após este tempo, encontra-se o equilíbrio.

\section{CONCLUSÕES}

O carvão ativado apresentou resultados satisfatórios, após 30 minutos de agitação, na adsorção do biodiesel de mamona, demonstrando seu poder de adsorção no tratamento do efluente de biodiesel.

Sugere-se o estudo de variáveis como temperatura, agitação, $\mathrm{pH}$ e massa de adsorvente, o que poderia tornar ainda mais viável o processo.

\section{AGRADECIMENTOS}

Agradecemos ao Programa PIBIC/UFAL e ao $\mathrm{CNPq}$ pelo auxílio à pesquisa.

A empresa BONECHAR pelo fornecimento de dados e doação do carvão ativado.

\section{REFERÊNCIAS}

AYGUN, A., KARAKAS, S. Y., DUMAN, I. (2003). Production of Granular Activated Carbon from Fruit Stones and Nutshells 
and Evaluation of their Physical, Chemical and Adsorption Properties.Microporous and Mesoporous Materials 66, 189-195.

COUTINHO, A.R.; BARBIERI, F.C.; PAVANI, P.A. (2000). "Preparação de Carvões Ativados a Partir de Fibras de Celulose". In: $2^{\circ}$ Encontro Brasileiro de Adsorção, maio de 1998, Florianópolis, Santa Catarina. Anais de trabalhos apresentados, Leonel T. Pinto (editor), Santa Catarina, SC.

FERNANDEZ, R.; JOSÉ, H. J.; MOREIRA, R. F. P. M. (2005). Adsorventes Alternativos para Remoção de Fenol em Solução Aquosa. Florianópolis, 70-71.

KHALED, A., NEMR, A. E., SIKAILY, A. E. \& ABDELWAHAB, O. (2009). Removal of Direct N Blue-106 from Artificial Textile DyeEffluent using Activated Carbon from Orange Peel: AdsorptionIsotherm and Kinetic Studies. JournalofHazardousMaterials165, 100110.

LOUREIRO, L. F. (2012). Avaliação da Adsorção do Herbicida 2,4-D em Carvão Ativado em Pó e Granular por Meio de Análises de Isotermasde Adsorção Utilizando Diferentes Qualidades de Água. Vitória, ES.

MALIK, P. K.. Use of Activated Carbons Prepared from Sawdust and Rice-husk for
Adsorption of Acid Dyes: a Case Study of Acid Yellow 36. Dyes and Pigments 56 (2003), 239-249.

NAMASIVAYAM, C.; KAVITHA, D. (2002). Removal of Congo Red fromWater by Adsorption onto Activated Carbon Prepared fromCoir Pith, an Agricultural Solid Waste. DyesandPigments54, 47-58.

NEVES, T. A. (2009). Tratamento físicoquímico dos efluentes líquidos da produção de biodiesel metílico em regime de funcionamento contínuo e em batelada. Cuiabá, MT.

NIEDERSBERG, C.; SCHNEIDER, R. C. S.; RODRIGUEZ, A. L. (2012). Ensaios de Adsorção com Carvão Ativado Produzido a Partir da Casca do Tungue (Aleuritesfordii), Resíduo do Processo de Produção de Óleo. Santa Cruz do Sul, 57 $-58$.

SOUZA, P. F.; SANTOS, E. G. (2007). Estudo da Remoção de Óleos e Graxas em Efluentes de Petróleo Utilizando Bagaço de Cana.

TAN, I. A. W., HAMEED, B. H., AHMAD, A. L. (2007). Equilibrium and Kinetic Studies on Basic Dye Adsorption by Oil Palm Fibre Activated Carbon.ChemicalEngineeringJournal 127, 111-119. 